\title{
Article \\ Melatonin, a Potential Therapeutic Agent for Preeclampsia, Reduces the Extrusion of Toxic Extracellular Vesicles from Preeclamptic Placentae
}

\author{
Yunhui Tang ${ }^{1,2, *}$, Katie Groom ${ }^{3,4}$, Larry Chamley ${ }^{2,5}$ and Qi Chen ${ }^{2,5, *(D)}$ \\ 1 Department of Family Planning, The Hospital of Obstetrics \& Gynaecology, Fudan University, \\ Shanghai 200081, China \\ 2 Department of Obstetrics and Gynaecology, The University of Auckland, 1142 Auckland, New Zealand; \\ 1.chamley@auckland.ac.nz \\ 3 National Women's Health, Auckland City Hospital, 1142 Auckland, New Zealand; k.groom@auckland.ac.nz \\ 4 Liggins Institute, The University of Auckland, 1142 Auckland, New Zealand \\ 5 Hub for Extracellular Vesicle Investigations, The University of Auckland, 1142 Auckland, New Zealand \\ * Correspondence: tangyunhui1786@fckyy.org.cn (Y.T.); q.chen@auckland.ac.nz (Q.C.)
}

Citation: Tang, Y.; Groom, K.; Chamley, L.; Chen, Q. Melatonin, a Potential Therapeutic Agent for Preeclampsia, Reduces the Extrusion of Toxic Extracellular Vesicles from Preeclamptic Placentae. Cells 2021, 10 , 1904. https://doi.org/10.3390/ cells10081904

Academic Editors: Junie P Warrington, Ana T. Palei, Mark W. Cunningham, Lorena M. Amaral and Alexander Kalyuzhny

Received: 7 June 2021

Accepted: 23 July 2021

Published: 27 July 2021

Publisher's Note: MDPI stays neutral with regard to jurisdictional claims in published maps and institutional affiliations.

Copyright: (c) 2021 by the authors. Licensee MDPI, Basel, Switzerland. This article is an open access article distributed under the terms and conditions of the Creative Commons Attribution (CC BY) license (https:/ / creativecommons.org/licenses/by/ $4.0 /)$.

\begin{abstract}
Preeclampsia, characterised by maternal endothelial cell activation, is triggered by toxic factors, such as placental extracellular vesicles (EVs) from a dysfunctional placenta. The increased oxidative stress seen in the preeclamptic placenta links to endoplasmic reticulum (ER) stress. The ER regulates protein folding and trafficking. When the ER is stressed, proteins are misfolded, and misfolded proteins are toxic. Misfolded proteins can be exported from cells, via EVs which target to other cells where the misfolded proteins may also be toxic. Melatonin is a hormone and antioxidant produced by the pineal gland and placenta. Levels of melatonin are reduced in preeclampsia. In this study we investigated whether melatonin treatment can change the nature of placental EVs that are released from a preeclamptic placenta. EVs were collected from preeclamptic $(n=6)$ and normotensive $(n=6)$ placental explants cultured in the presence or absence of melatonin for $18 \mathrm{~h}$. Misfolded proteins were measured using a fluorescent compound, Thioflavin-T (ThT). Endothelial cells were exposed to placental EVs overnight. Endothelial cell activation was measured by the quantification of cell-surface ICAM-1 using a cell-based ELISA. EVs from preeclamptic placentae carried significantly $(p<0.001)$ more misfolded proteins than normotensive controls. Incubating preeclamptic placental explants in the presence of melatonin $(1 \mu \mathrm{M}$ and $10 \mu \mathrm{M})$ significantly $(p<0.001)$ reduced the misfolded proteins carried by EVs. Culturing endothelial cells in the presence of preeclamptic EVs significantly increased the expression of ICAM-1. This increased ICAM-1 expression was significantly reduced when the endothelial cells were exposed to preeclamptic EVs cultured in the presence of melatonin. This study demonstrates that melatonin reduces the amount of misfolded proteins carried by EVs from preeclamptic placentae and reduces the ability of these EVs to activate endothelial cells. Our study provides further preclinical support for the use of melatonin as a treatment for preeclampsia.
\end{abstract}

Keywords: melatonin; extracellular vesicle; exosome; preeclampsia; misfold proteins; endothelial cell activation

\section{Introduction}

Preeclampsia, a human specific pregnancy disorder, is clinically characterised by high blood pressure after 20 weeks of gestation accompanied by one or more of a spectrum of signs of organ dysfunction [1,2]. It affects $2-8 \%$ of all pregnancies worldwide [1,2]. The clinical signs of preeclampsia are preceded by an exaggerated inflammatory response and generalised maternal endothelial cell dysfunction, which are fundamental components of the pathogenesis of preeclampsia [3]. Dysfunctional endothelial cells consequently prevent the normal adaptation of the maternal vasculature seen in pregnancy, with resulting hypertension and other signs and symptoms of preeclampsia. Although the underlying 
mechanisms of preeclampsia are still not fully understood, it is recognised that one or more toxic factors released from the placenta trigger the maternal endothelial dysfunction. Extracellular vesicles (EVs) are among the placental factors that are increasingly recognised as being able to contribute to the endothelial cell dysfunction of preeclampsia [4-6].

EVs are lipid-enclosed packages of cellular contents that are extruded from all cells. Most eukaryote cells extrude both micro- and nano-EVs. While there are varying definitions, generally micro-EVs range in size from 200 to $1000 \mathrm{~nm}$, while nano-EVs range from 10 to $200 \mathrm{~nm}$. A subpopulation of nano-EVs are exosomes. The maternal-facing aspect of the human placenta is covered entirely by a single multinucleated cell, the syncytiotrophoblast, which extrudes vast numbers of both micro- and nano-EVs directly into the maternal circulation. These placental EVs are carried around the maternal body and can interact with multiple maternal cells and organs, including endothelial cells $[7,8]$. Like EVs from other cell types, placental EVs contain biologically active proteins, nucleic acids, lipids and RNAs, that they can transfer to recipient cells and organs, affecting their function [9-12]. We and others have previously reported that placental EVs derived from preeclamptic placentae activated maternal endothelial cells in vitro and shown that nano-EVs alter the maternal vascular tone in pregnant mice [10,13-15].

Oxidative stress is significantly increased in the preeclamptic placenta [16], and there is a strong connection between oxidative stress and endoplasmic reticulum (ER) stress [17]. The ER regulates protein folding and trafficking. When the ER is stressed, proteins are misfolded, and misfolded proteins can then be exported from cells or tissues, via EVs which target to other cells where the misfolded proteins may be toxic. We have recently shown that preeclamptic placentae contained significantly more aggregated transthyretin than normotensive placentae and that this transthyretin is specifically packaged into nanoEVs [18].

Melatonin is a lipid-soluble hormone with antioxidant activities originally identified as being of primarily pineal origin. However, melatonin is also produced in large quantities by the placenta $[19,20]$. In addition to its endocrine functions, melatonin also has direct free radical scavenging and indirect antioxidant activities [21-24]. The peak melatonin levels in pregnancy are $80-100 \mathrm{pg} / \mathrm{mL}$, twice as high as those in men or non-pregnant women. Much of the melatonin is of placental origin, suggesting a particular importance of melatonin in pregnancy $[19,25-28]$. However, women with preeclampsia have significantly decreased serum levels of melatonin [25,26], as well as decreased levels of the enzymes responsible for melatonin synthesis and decreased levels of melatonin receptors [29]. Given the action of melatonin in modulating free radicals/oxidative stress and a potential role in the treatment of preeclampsia [30-32], we undertook this study to investigate whether melatonin supplementation has a preventative effect on the production of toxic placental EVs from preeclamptic placentae.

\section{Methods}

This study was approved by the Northern $X$ Health and Disabilities Ethics Committee, New Zealand (NTX/12/06/057/AM06), and conforms to the principles outlined in the Declaration of Helsinki. All patient-derived tissues were obtained following informed written consent.

\section{Collection of Preeclamptic Placentae}

Six placentae were collected from women with preeclampsia (two of them in an early onset and four of them in a late onset form), and ten term placentae were collected from normotensive pregnancies from National Women's Health, Auckland City Hospital, New Zealand. The clinical parameters of the study cohort are summarised in Table 1. We were not able to collect gestation-matched placentae from normotensive pregnancies due to ethical issues. There was no difference in the maternal age $(p=0.388)$ between the two groups. All women with preeclampsia received medication, either labetalol or nifedipine. The mean BMI in preeclampsia was $27.08 \pm 5.2 \mathrm{~kg} / \mathrm{m}^{2}$. 
Table 1. Clinical parameters of the study cohort.

\begin{tabular}{ccc}
\hline & Preeclampsia $(\boldsymbol{n}=\mathbf{6})$ & Normotensive $(\boldsymbol{n}=\mathbf{1 0})$ \\
\hline Maternal age (years, mean/SD) & $30.2 \pm 3.1$ & $32 \pm 5.1$ \\
\hline Onset week (mean/SD) & $33+6 \pm 4$ & N/A \\
\hline Delivery week & $35+2 \pm 4$ & $39 \pm 1$ \\
\hline Birthweight $(\mathrm{g}, \mathrm{mean} / \mathrm{SD})$ & $2365 \pm 338$ & $3350 \pm 180$ \\
\hline Systolic blood pressure (mmHg, mean/SD) & $156 \pm 7$ & N/A \\
\hline
\end{tabular}

Preeclampsia was defined as a maternal systolic blood pressure $\geq 140 \mathrm{mmHg}$ and /or diastolic blood pressure $\geq 90 \mathrm{mmHg}$ on two occasions separated by $6 \mathrm{~h}$, and proteinuria $>300 \mathrm{mg}$ in a $24 \mathrm{~h}$ period, a protein-creatinine ratio $>30 \mathrm{mg} / \mathrm{mmol}$ or impaired liver function after 20 weeks of gestation, in accordance with the guideline of the Society of Obstetric Medicine of Australia and New Zealand (SOMANZ), which are consistent with the international guideline from the International Society for the Study of Hypertension in Pregnancy (ISSHP) [33].

\section{Collection of Placental EVs from Preeclamptic Placentae}

Approximately $400 \mathrm{mg}$ wet weight placental explants were dissected from either preeclamptic or normotensive placentae, as previously described [13,34,35]. Four quadruplicate explants from each placenta were cultured in Netwell ${ }^{\mathrm{TM}}$ culture inserts and suspended in 12 well culture plates, for $24 \mathrm{~h}$ at $37^{\circ} \mathrm{C}$, in $3 \mathrm{~mL}$ Advanced DMEM/F12 containing 2.5\% fetal bovine serum in an ambient oxygen atmosphere in the presence or absence of melatonin ( $1 \mu \mathrm{M}$ and $10 \mu \mathrm{M}$, dissolved in PBS) (Sigma-Aldrich, Auckland, New Zealand). The concentration of melatonin followed that of our previous study [36]. As our previous study [36] showed no dose response on the effect of melatonin, in this study normotensive placental explants were treated with a higher dose of melatonin $(10 \mu \mathrm{M})$. The conditioned media were then collected and centrifuged at $2000 \times g$ for $5 \mathrm{~min}$ for the removal of culture debris. The supernatant was centrifuged at $20,000 \times g$ for $1 \mathrm{~h}$ for the collection of micro-EVs. The supernatant was further centrifuged at $100,000 \times g$ for $1 \mathrm{~h}$ for collection of nano-EVs (Avanti J30 I Ultracentrifuge, JA 30.50 fixed angle rotor, Beckman Coulter, New Zealand).

The relevant cultured explants with melatonin treatment were then collected and immediately embedded in an optimal cutting temperature (OCT) compound, and then sectioned at $5 \mu \mathrm{m}$ using a cryostat for the measurement of misfolded proteins.

\section{Quantification of Micro-EVs and Nano-EVs}

The amount of micro- and nano-EVs collected from preeclamptic and healthy placentae were quantified using a Nanosight ${ }^{\mathrm{TM}}$ NS300 nanoparticle tracking device (Nanosight, UK). Placental micro-EVs and nano-EVs were re-suspended in $1 \mathrm{~mL}$ PBS after ultra-centrifugation and analysed. All automatic settings were applied, with the viscosity setting at $0.95 \mathrm{cP}$ and the temperature at $25^{\circ} \mathrm{C}$. A single measurement consists of three 30 -s videos, and each sample was measured five times at camera level 10. The detection threshold was set at 10, and data acquisition and processing were performed using the NTA3.2 software (Nanosight). Only recordings with over 1000 valid tracks/vesicles were included in the analysis. The number of placental EVs was expressed as the number of EVs per $\mathrm{mL}$.

\section{Measurement of Endothelial Cell Activation by Cell-Based ELISA}

A human microvascular endothelial cell line, composed of HMEC-1 cells (ATCC, CRL-3243), was grown until confluent in 96 well culture plates in MCDB 131 media. The endothelial cells (HMEC-1) were exposed to placental micro- or nano-EVs from preeclamptic placental explants or from normotensive placental explants which had been treated with or without melatonin for $24 \mathrm{~h}$. After the removal of the remaining placental EVs by 
washing with PBS, the cell surface expression of ICAM-1 by HMEC-1 monolayers was determined by a cell-based ELISA, as described previously [13]. Each measurement of ICAM-1 was conducted in quadruplicate. The data are presented as the median and 5th and 95th percentiles of the fold changes relative to untreated controls.

\section{Measurement of Misfolded Proteins}

Misfolded proteins in preeclamptic and healthy placentae and in the preeclamptic placental explants that had been treated with melatonin were measured using a fluorescent compound, Thioflavin-T (ThT, Sigma-Aldrich, Sydney, Australia), as described previously [37,38]. Briefly, frozen placental sections $(5 \mu \mathrm{m})$ were fixed with $4 \%$ paraformaldehyde (PFA) for $5 \mathrm{~min}$ at room temperature and washed with PBS. The sections were then stained with ThT (500 $\mu \mathrm{M}$ dissolved in PBS) for $3 \mathrm{~min}$ at room temperature, followed by counter-staining with DAPI for $1 \mathrm{~min}$. The sections were then mounted with Citifluor and examined using a fluorescent microscope (Nikon, ECLISPE Ni-E, Tokyo, Japan). Sections from which ThT was omitted were used as negative controls.

Misfolded proteins in micro- or nano-EVs collected from preeclamptic or healthy placental explant cultures that had been treated with melatonin were stained with ThT $(5 \mu \mathrm{M})$ for $10 \mathrm{~min}$ and read in a fluorescent plate reader at $485 \mathrm{~nm}$ (Synergie 2, BioTek, Auckland, New Zealand), following previous reports $[37,38]$.

\section{Semiquantitative Analysis of Immunofluorescent Staining}

All images were converted into a 32-bit RGB colour format. Subsequently, a representative mean grey value integral was quantified from each image, which served as an index for fluorescence intensity and allowed for relative comparisons of protein expression between different images and samples. Each image was opened using ImageJ software, and five lines were randomly drawn on the images. The fluorescent density of each line on the images was calculated by Matlab software (R2019 A version). The resultant five integral values were averaged to yield a mean grey value integral [39].

\section{Statistical Analysis}

The concentrations of placental micro- and nano-EVs were expressed as a median and $95 \%$ confidence interval (CI). The statistical analysis of the concentration of placental micro- or nano-EVs, the levels of expression of cell surface ICAM-1 by endothelial cells or the levels of misfolded proteins in placental EVs were assessed with an ANOVA test, or a Mann-Whitney U-test, when appropriate. The GraphPad Prism software package (version 8.0 ) was used, and a $p<0.05$ was considered as statistically significant.

\section{Results}

10.1. The Amount of Placental EVs Extruded from Preeclamptic Placentae Was Not Changed by Treatment with Melatonin

We confirmed previous reports [40] that the amount of micro- and nano-EVs extruded from preeclamptic placentae was significantly increased compared to the number of EVs released from normotensive placental explants (Figure 1A, $p=0.016$, or Figure 1B, $p<0.01$, respectively). The treatment with melatonin (either $1 \mu \mathrm{M}$ or10 $\mu \mathrm{M}$ ) did not change the amount of micro-EVs (Figure 1A, $p=0.954$, ANOVA) or nano-EVs (Figure 1B, $p=0.776$, ANOVA) extruded from preeclamptic placental explant cultures.

\subsection{Treatment with Melatonin Prevented the Production of Toxic Placental EVs from Preeclamptic Placentae}

We confirmed that placental EVs from preeclamptic placentae activated endothelial cells (Figure 2A,B, $p<0.001$ ), which was previously reported [41]. Both the micro-EVs and nano-EVs released from preeclamptic placental explants that had been incubated with melatonin did not induce an increase in endothelial cell activation (as measured by cell surface ICAM-1 expression, Figure 2A, $p=0.0014$, ANOVA or Figure 2B, $p=0.0002$, 
ANOVA). There was no dose response in the reduction of ICAM-1 levels $(p>0.05)$ across the concentrations of melatonin tested.

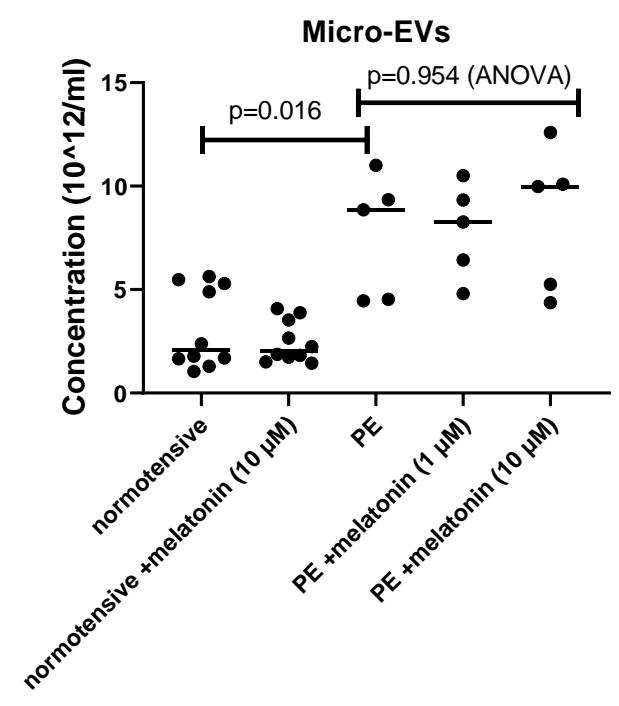

(A)

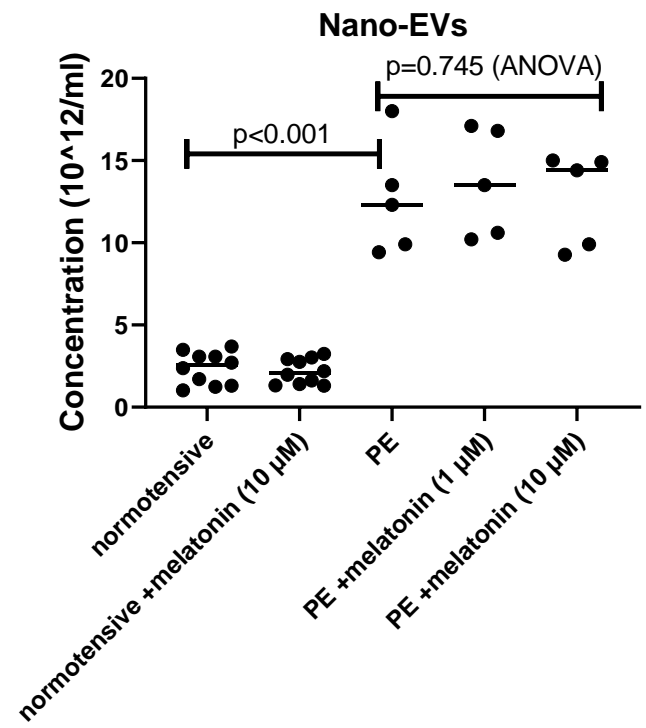

(B)

Figure 1. The numbers of micro- (A) or nano-EVs (B) extruded from preeclamptic placentae (PE) was quantified by NTA, and the statistical analyses were assessed with an ANOVA test or a MannWhitney U-test, when appropriate.

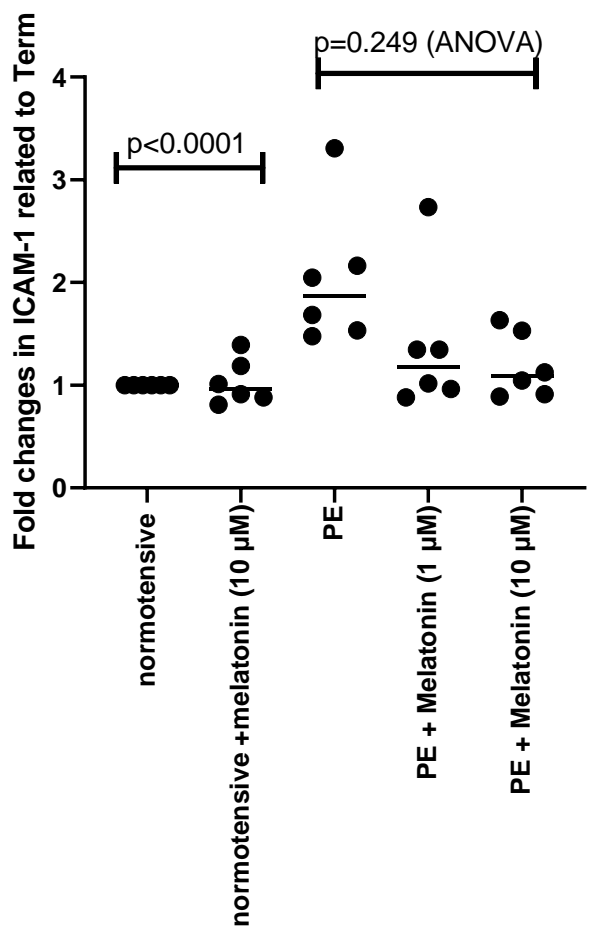

Micor EVs treatment

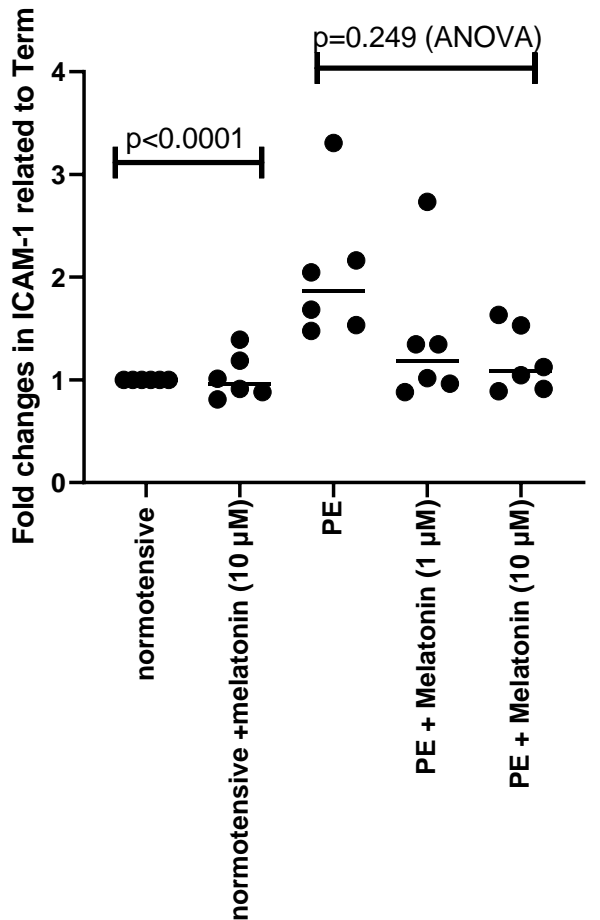

Micor EVs treatment

(A)

(B)

Figure 2. The activation of endothelial cells after being exposed to micro- (A) or nano-EVs (B) extruded from preeclamptic (PE) or normotensive placentae was measured by cell-surface ICAM-1 levels. The statistical analysis was assessed by an ANOVA test or a Mann-Whitney U-test, when appropriate. 
10.3. Treatment with Melatonin Reduced the Levels of Misfolded Proteins in Preeclamptic Placentae and in Placental EVs from Preeclamptic Placentae

There were significantly increased levels of misfolded proteins in micro- (Figure 3A, $p=0.0001$ ) and nano-EVs (Figure $3 \mathrm{~B}, p=0.0001$ ) collected from preeclamptic placentae compared to placental EVs collected from normotensive term placental explants, measured by the fluorescent intensity of ThT (measured at $485 \mathrm{~nm}$ ). However, this increased fluorescent intensity of ThT was significantly reduced when placental EVs were collected from melatonin-treated (1 or $10 \mu \mathrm{M})$ preeclamptic placental explant cultures (Figure $3 \mathrm{~A}, \mathrm{~B}$, $p=0.0001$, ANOVA). There was no dose response in the reduction of the fluorescent intensity of ThT.

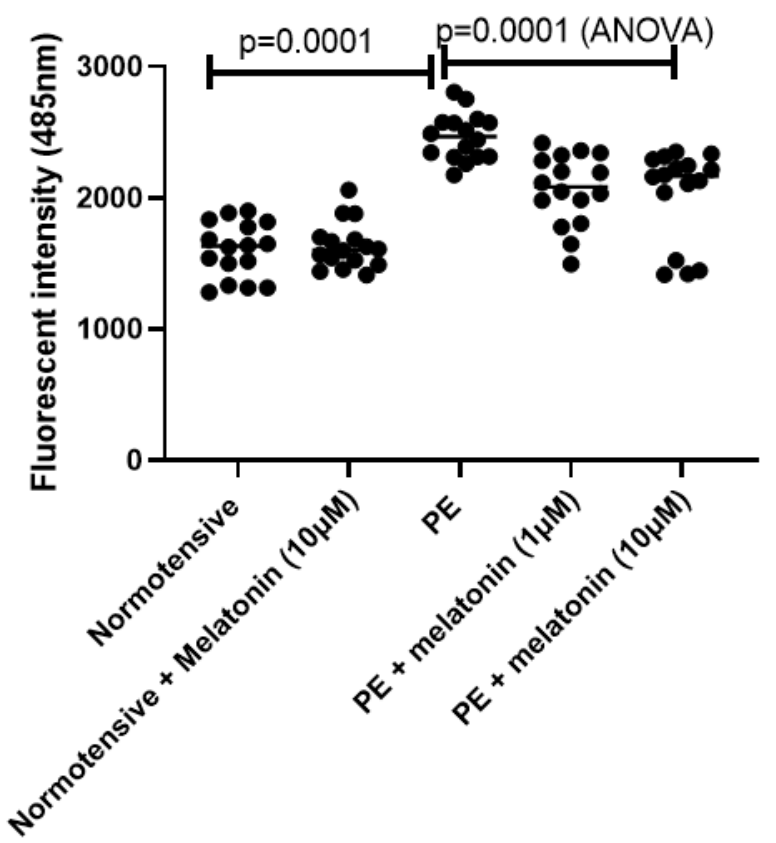

Micro-EVs

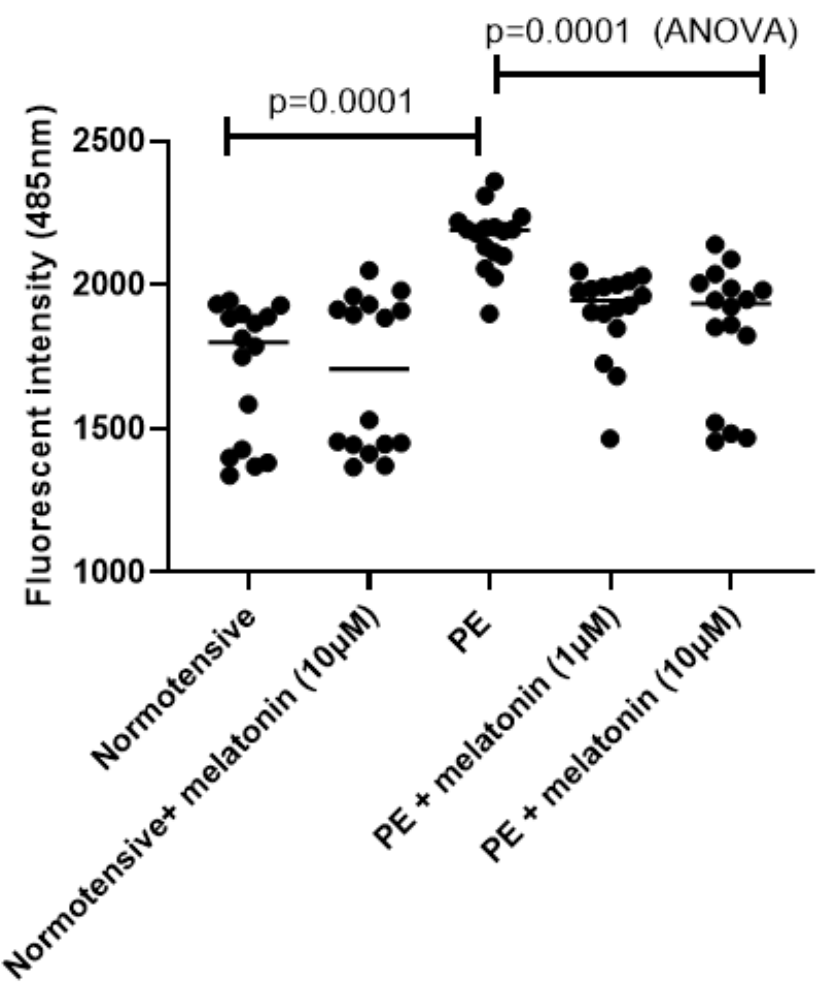

Nano-EVs

(A)

(B)

Figure 3. The misfolded proteins in placental micro-EVs (A) and nano-EVs (B) collected from either preeclamptic (PE) or normotensive placentae were measured by ThT fluorescent intensity. The statistical analysis was assessed by an ANOVA test or a Mann-Whitney U-test, when appropriate.

In addition, there were significantly increased levels of misfolded proteins in preeclamptic placentae (Figure 4A), compared to normotensive placentae (Figure 4B), measured by the increased fluorescent intensity levels of ThT in a semi-quantitative assay (Figure $4 \mathrm{C}, p$ $=0.0079)$. However, the treatment of the preeclamptic placentae with melatonin $(1 \mu \mathrm{M}$ Figure $5 \mathrm{~B}$ or $10 \mu \mathrm{M}$ Figure $5 \mathrm{C}$ ) significantly reduced the fluorescent intensity of ThT in preeclamptic placentae, compared to the untreated ones (Figure 5A), measured by a semiquantitative assay (Figure 5E, $p<0.0001$ ). There was also no dose response in the reduction of the fluorescent intensity of ThT (Figure 5E, $p>0.05$ ). 

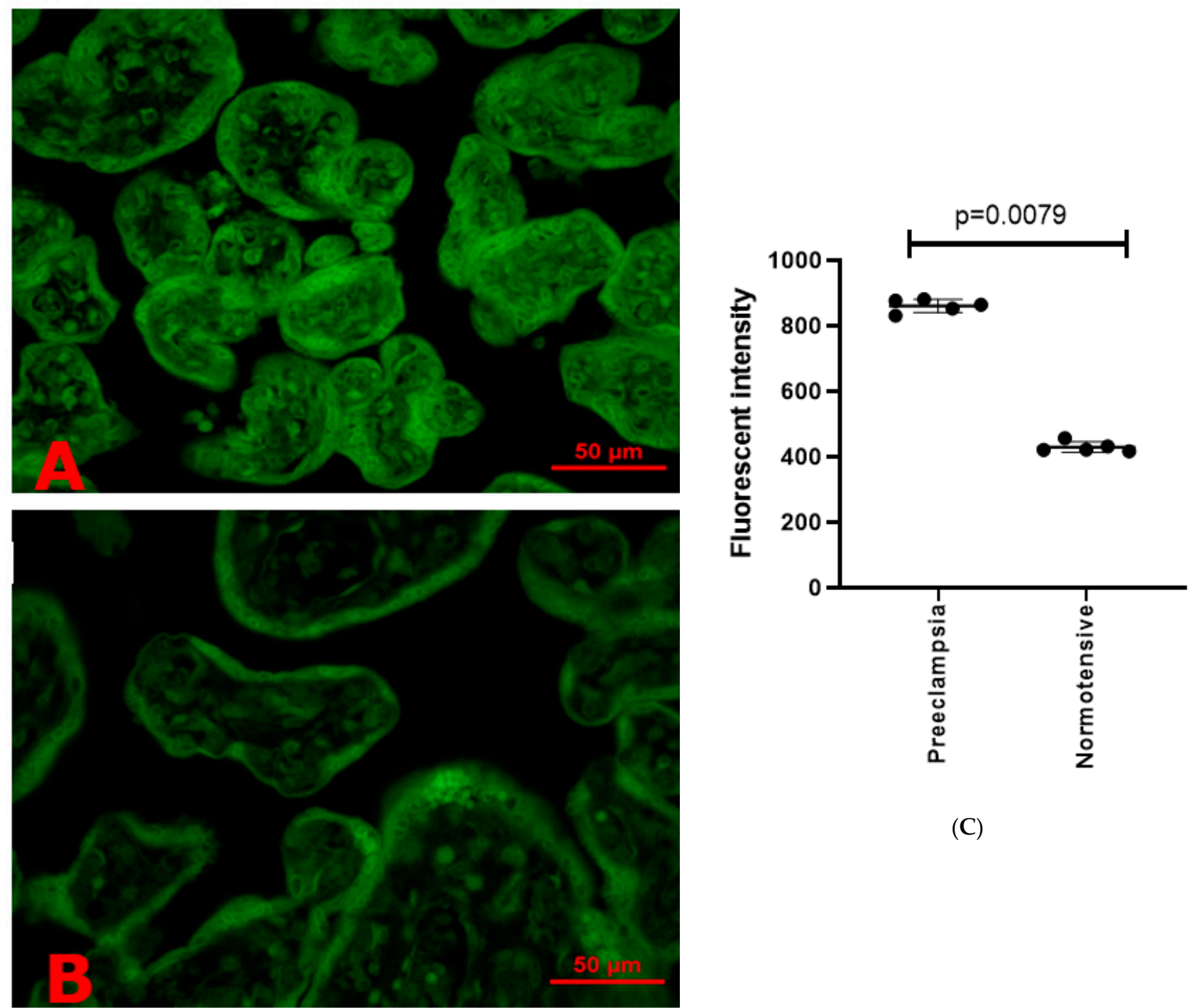

(C)

Figure 4. The levels of misfolded proteins in preeclamptic placentae, especially in the syncytiotrophoblast (A) and in normotensive term placentae (B), were measured by ThT fluorescent intensity. The statistical difference was confirmed by a semi-quantitative assay $(\mathbf{C})$. 

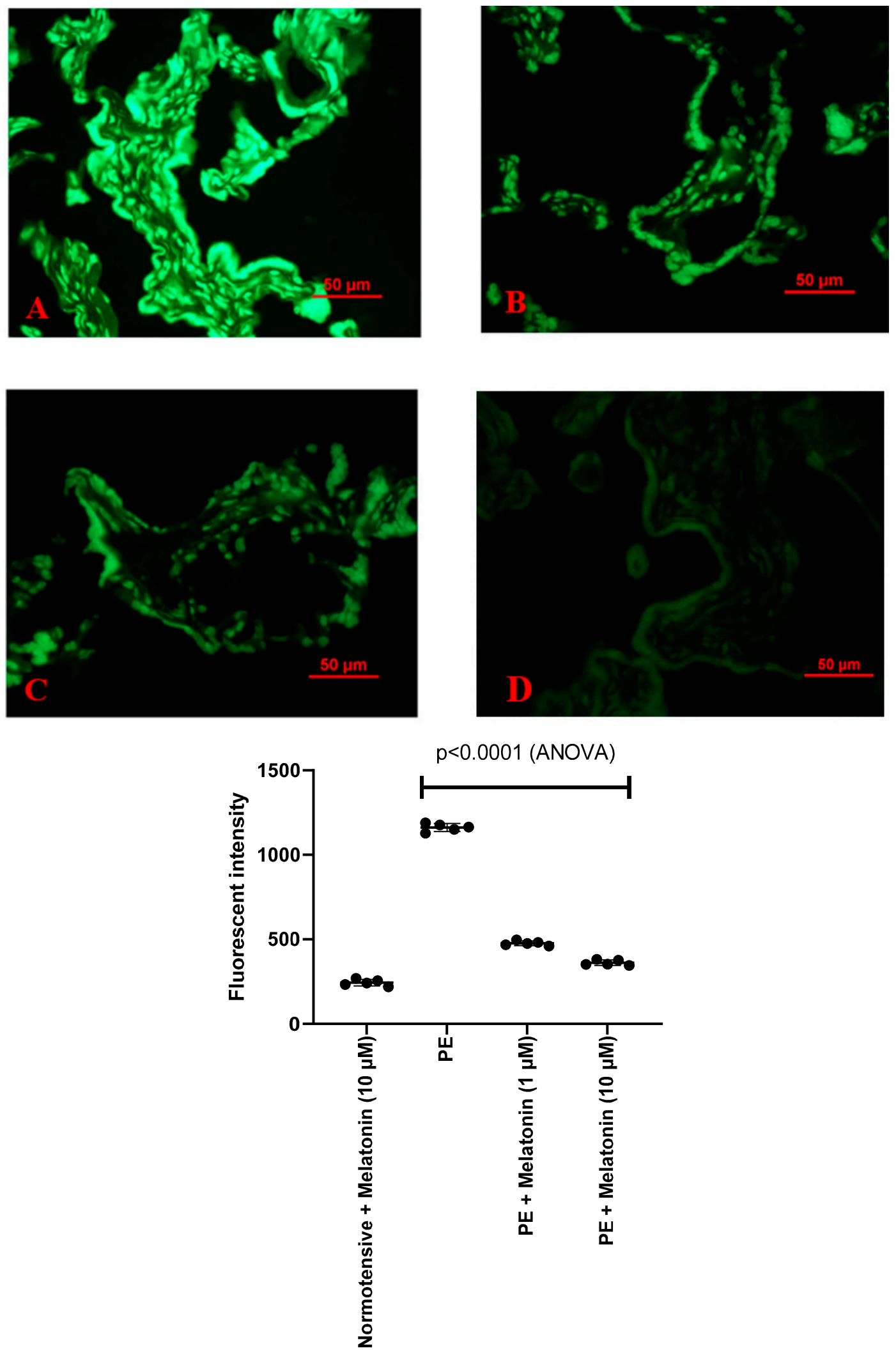

(E)

Figure 5. Misfolded proteins in preeclamptic placental explants (PE) that had been treated with $1 \mu \mathrm{M}(\mathbf{B})$ or $10 \mu \mathrm{M}(\mathbf{C})$ melatonin or without melatonin (A) were measured by the fluorescent intensity of ThT. In comparison, misfold proteins in normotensive placental explants that had been treated with $10 \mu \mathrm{M}(\mathrm{D})$ were also measured. The statistical difference was confirmed by a semi-quantitative assessment and assessed by an ANOVA test (E). 


\section{Discussion}

In this in vitro study, we found that the treatment with melatonin did not reduce the amount of EVs produced by preeclamptic placentae but did alter the nature (function) of the EVs such that they were not toxic and did not active endothelial cells. Reducing the increased levels of ER stress in preeclamptic placentae and in EVs that were exported from preeclamptic placentae could be one of the underlying mechanisms of this protective effect of endothelial cell activation.

Although the exact causes of preeclampsia are still unclear, there is increasing evidence suggesting that EVs extruded from the placenta are associated with the pathogenesis of preeclampsia [13]. These placental EVs from preeclamptic placentae may contribute to triggering the disease by inducing maternal systemic endothelial cell dysfunction [42], as they carry several anti-angiogenic factors, including soluble fms-like tyrosine kinase-1 (sFlt1) and soluble Endoglin (sEng), cytokines and oxidants, as well as multiple "danger" signals [43]. Oxidative stress results from an imbalance in oxidant and antioxidant molecules [44] and is reported to play an important role in the development of preeclampsia [45].

Melatonin, typically thought of as a lipid hormone that regulates circadian rhythms, has been shown to have direct free-radical scavenging properties and to induce the expression of antioxidants [46]. During pregnancy, the placenta is a major source of melatonin, producing higher levels than the pineal gland [20], and placental melatonin production does not appear to be regulated in a circadian fashion [47]. Studies have suggested that alterations of circadian rhythms increase the risk of developing preeclampsia [48]. In women with preeclampsia there are significantly reduced levels of circulating melatonin $[25,26]$, accompanied by a reduction in the levels of the synthetic enzymes and melatonin receptors in preeclamptic placentae [29]. Therefore, it has been suggested that exogenous melatonin may have potential benefits in preeclampsia [30-32,48,49]. Here, we confirmed that EVs from preeclamptic placentae induce endothelial cell activation, which is a hallmark of preeclampsia, and found that EVs from preeclamptic placental explants that had been treated with melatonin did not induce endothelial cell activation. This finding fits with our previous report that melatonin reversed the production of toxic placental EVs extruded from normal placental explants that had been treated with either preeclamptic serum or antiphospholipid antibodies, which are a major maternal risk factor for preeclampsia [50]. In our previous report, we demonstrated that treating placental explants with melatonin reduced the markers of oxidative stress that were induced by the preeclamptic sera and antiphospholipid antibodies [36]. Others have recently shown that melatonin induces the expression of antioxidants in the placenta [51]. Taken together, our data further suggest that exogenous melatonin could directly change the production of toxic EVs by the preeclamptic placenta.

The molecular signalling pathways that change the production of EVs in preeclampsia are largely unknown. A number of factors found in preeclampsia, such as the inflammatory cytokines IL-6 and TNF $\alpha$ [52], disrupt placental function, resulting in the production of toxic EVs [53]. Exactly how those cytokines induce the production of toxic EVs is still unclear, but more is known about how antiphospholipid antibodies induce the production of toxic EVs $[54,55]$. These autoantibodies are internalised into the syncytiotrophoblast where they cause mitochondrial dysfunction, oxidative damage, the production of both necroptosis and apoptosis cell death pathway proteins and ER stress, characterised by an excess of misfolded proteins [38,56]. ER stress is a feature of preeclamptic placentae that is characterised by increased protein misfolding and aggregation (reviewed in [57]). These misfolded and aggregated proteins are toxic and can be deported from the placenta into the maternal circulation via EVs. For example, we have previously shown increased levels of aggregated transthyretin in EVs extruded from preeclamptic placentae [18]. Removing misfolded proteins via EVs may be a survival mechanism for the syncytiotrophoblast, but these misfolded proteins are potentially damaging to the maternal cells that take up the EVs containing an excess of misfolded proteins. Here, we confirmed an increased level of misfolded proteins in preeclamptic placentae. In addition, we also found an increased level 
of misfolded proteins in both micro- and nano-EVs extruded from preeclamptic placentae. These EVs are targeted to several maternal organs, such as the liver and kidneys, that are often effected in preeclampsia $[9,10]$. The uptake of micro-EVs and/or nano-EVs that contain toxic misfolded proteins may be harmful to these organs. The key finding of our current study is that treating explants from preeclamptic placentae with melatonin reduces the levels of misfolded proteins both in the placenta and in the EVs extruded from the placentae. The reduction of the load of misfolded proteins delivered to maternal organs by EVs from melatonin-treated preeclamptic placentae may reduce the harm to those organs. The clinical utility of melatonin for the treatment of preeclampsia has recently been suggested by a phase I clinical trial that demonstrated the safety of administering melatonin to women with preeclampsia and also demonstrated a prolongation of the time from diagnosis to delivery [58].

We acknowledge that, due to the small clinical samples used in this study, we were not able to analyse whether the protective effect on producing toxic placental EVs by melatonin is associated with the severity or time of onset of preeclampsia. Future study is required to confirm our findings.

In conclusion: this study demonstrates that exogenous melatonin prevents the production of endothelial-activating EVs from preeclamptic placentae. Reducing the amount of misfolded proteins carried by EVs from preeclamptic placentae exporting to the maternal circulation may be one of the underlying mechanisms to prevent endothelial cell activation. Our study provides further preclinical support for the use of melatonin for the treatment of preeclampsia.

Author Contributions: All authors were involved in the drafting, editing and approval of the manuscript for publication. In addition to this, each author contributed to the following work: Y.T. and Q.C.: experiments performance and analysis; L.C. and Q.C.: data analysis; K.G., L.C. and Q.C.: designed the study and wrote the manuscript draft. All authors have read and agreed to the published version of the manuscript.

Funding: This research was supported by grants from the Performance Based Research Foundation (PBRF), the School of Medicine, The University of Auckland, and the Health Research Council of New Zealand (grant number 18/408). Y.T. was funded by training grants from The Hospital of Obstetrics and Gynaecology, Fudan University, China. The APC was funded by The Hospital of Obstetrics and Gynaecology, Fudan University, China.

Institutional Review Board Statement: This study was approved by the Northern X Health and Disabilities Ethics Commit-tee, New Zealand (NTX/12/06/057/AM06).

Informed Consent Statement: All patient-derived tissues were obtained following informed written consent.

Data Availability Statement: All the data will be available upon to request.

Acknowledgments: The authors thank the patients and staff of Auckland City Hospital for the donation and collection of placentae.

Conflicts of Interest: None of the authors has a conflict of interest to declare.

\section{References}

1. Sibai, B.; Dekker, G.; Kupferminc, M. Pre-eclampsia. Lancet 2005, 365, 785-799. [CrossRef]

2. Gestational Hypertension and Preeclampsia: ACOG Practice Bulletin, Number 222. Obstet. Gynecol. 2020, 135, e237-e260. [CrossRef] [PubMed]

3. Roberts, J.M. Endothelial dysfunction in preeclampsia. Semin. Reprod. Endocrinol. 1998, 16, 5-15. [CrossRef] [PubMed]

4. Schmorl, G. Pathologisch-Anatomische Untersuchungen Uber Puerperal-Eklampsie; Verlag von FC Vogel: Leipzig, Germany, 1893.

5. Attwood, H.; Park, W. Embolism to the lungs by trophoblast. BJOG Int. J. Obstet. Gynaecol. 1961, 68, 611-617. [CrossRef]

6. Jaameri, K.E.; Koivuniemi, A.P.; Carpen, E.O. Occurrence of trophoblasts in the blood of toxaemic patients. Gynaecologia 1965, 160, 315-320. [CrossRef]

7. Tong, M.; Stanley, J.L.; Chen, Q.; Wise, M.R.; Stone, P.R.; James, J.L.; Chamley, L.W. In Vivo Targets of Human Placental Extracellular Vesicles. Reprod. Sci. 2016, 23, 153a. 
8. Cronqvist, T.; Tannetta, D.; Mörgelin, M.; Belting, M.; Sargent, I.; Familari, M.; Hansson, S.R. Syncytiotrophoblast derived extracellular vesicles transfer functional placental miRNAs to primary human endothelial cells. Sci. Rep. 2017, 7, 4558. [CrossRef]

9. Tong, M.; Chen, Q.; James, J.L.; Wise, M.R.; Stone, P.R.; Chamley, L.W. In vivo targets of human placental micro-vesicles vary with exposure time and pregnancy. Reproduction 2017, 153, 835-845. [CrossRef]

10. Tong, M.; Stanley, J.L.; Chen, Q.; James, J.L.; Stone, P.R.; Chamley, L.W. Placental Nano-vesicles Target to Specific Organs and Modulate Vascular Tone In Vivo. Hum. Reprod. 2017, 32, 2188-2198. [CrossRef] [PubMed]

11. Wei, J.; Blenkiron, C.; Tsai, P.; James, J.L.; Chen, Q.; Stone, P.R.; Chamley, L.W. Placental trophoblast debris mediated feto-maternal signalling via small RNA delivery: Implications for preeclampsia. Sci. Rep. 2017, 7, 14681. [CrossRef] [PubMed]

12. Wei, J.; Lau, S.Y.; Blenkiron, C.; Chen, Q.; James, J.L.; Kleffmann, T.; Wise, M.; Stone, P.R.; Chamley, L.W. Trophoblastic debris modifies endothelial cell transcriptome in vitro: A mechanism by which fetal cells might control maternal responses to pregnancy. Sci. Rep. 2016, 6, 30632. [CrossRef]

13. Chen, Q.; Stone, P.R.; McCowan, L.M.; Chamley, L.W. Phagocytosis of necrotic but not apoptotic trophoblasts induces endothelial cell activation. Hypertension 2006, 47, 116-121. [CrossRef]

14. Chen, Q.; Stone, P.; Ching, L.M.; Chamley, L. A role for interleukin-6 in spreading endothelial cell activation after phagocytosis of necrotic trophoblastic material: Implications for the pathogenesis of pre-eclampsia. J. Pathol. 2009, 217, 122-130. [CrossRef] [PubMed]

15. Chen, Q.; Guo, F.; Liu, S.; Xiao, J.; Wang, C.; Snowise, S.; Stone, P.R.; Chamley, L.W. Calcium channel blockers prevent endothelial cell activation in response to necrotic trophoblast debris: Possible relevance to pre-eclampsia. Cardiovasc. Res. 2012, 96, 484-493. [CrossRef] [PubMed]

16. Burton, G.J.; Jauniaux, E. Oxidative stress. Best Pract. Res. Clin. Obstet. Gynaecol. 2011, 25, 287-299. [CrossRef]

17. Kritsiligkou, P.; Rand, J.D.; Weids, A.J.; Wang, X.; Kershaw, C.J.; Grant, C.M. Endoplasmic reticulum (ER) stress-induced reactive oxygen species (ROS) are detrimental for the fitness of a thioredoxin reductase mutant. J. Biol. Chem. 2018, 293, 11984-11995. [CrossRef] [PubMed]

18. Tong, M.; Cheng, S.B.; Chen, Q.; DeSousa, J.; Stone, P.R.; James, J.L.; Chamley, L.W.; Sharma, S. Aggregated transthyretin is specifically packaged into placental nano-vesicles in preeclampsia. Sci. Rep. 2017, 7, 6694. [CrossRef] [PubMed]

19. Kivela, A. Serum melatonin during human pregnancy. Acta Endocrinol. 1991, 124, 233-237. [CrossRef]

20. Lanoix, D.; Beghdadi, H.; Lafond, J.; Vaillancourt, C. Human placental trophoblasts synthesize melatonin and express its receptors. J. Pineal Res. 2008, 45, 50-60. [CrossRef]

21. Miller, S.L.; Yawno, T.; Alers, N.O.; Castillo-Melendez, M.; Supramaniam, V.G.; VanZyl, N.; Sabaretnam, T.; Loose, J.M.; Drummond, G.R.; Walker, D.W. Antenatal antioxidant treatment with melatonin to decrease newborn neurodevelopmental deficits and brain injury caused by fetal growth restriction. J. Pineal Res. 2014, 56, 283-294. [CrossRef]

22. Miller, S.L.; Wallace, E.M.; Walker, D.W. Antioxidant therapies: A potential role in perinatal medicine. Neuroendocrinology 2012, 96, 13-23. [CrossRef]

23. Hardeland, R. Antioxidative protection by melatonin: Multiplicity of mechanisms from radical detoxification to radical avoidance. Endocrine 2005, 27, 119-130. [CrossRef]

24. Storm, W.F.; Eddy, D.R.; Welch, C.B.; Hickey, P.A.; Fischer, J.; Cardenas, R. Cognitive performance following premature awakening from zolpidem or melatonin induced daytime sleep. Aviat. Space Environ. Med. 2007, 78, 10-20. [PubMed]

25. Zeng, K.; Gao, Y.; Wan, J.; Tong, M.; Lee, A.C.; Zhao, M.; Chen, Q. The reduction in circulating levels of melatonin may be associated with the development of preeclampsia. J. Hum. Hypertens. 2016, 30, 666-671. [CrossRef]

26. Nakamura, Y.; Tamura, H.; Kashida, S.; Takayama, H.; Yamagata, Y.; Karube, A.; Sugino, N.; Kato, H. Changes of serum melatonin level and its relationship to feto-placental unit during pregnancy. J. Pineal Res. 2001, 30, 29-33. [CrossRef]

27. Rosell, R.; Danenberg, K.D.; Alberola, V.; Bepler, G.; Sanchez, J.J.; Camps, C.; Provencio, M.; Isla, D.; Taron, M.; Diz, P.; et al. Ribonucleotide reductase messenger RNA expression and survival in gemcitabine/cisplatin-treated advanced non-small cell lung cancer patients. Clin. Cancer Res. 2004, 10, 1318-1325. [CrossRef]

28. Sae-Teaw, M.; Johns, J.; Johns, N.P.; Subongkot, S. Serum melatonin levels and antioxidant capacities after consumption of pineapple, orange, or banana by healthy male volunteers. J. Pineal Res. 2013, 55, 58-64. [CrossRef]

29. Lanoix, D.; Guerin, P.; Vaillancourt, C. Placental melatonin production and melatonin receptor expression are altered in preeclampsia: New insights into the role of this hormone in pregnancy. J. Pineal Res. 2012, 53, 417-425. [CrossRef] [PubMed]

30. Reiter, R.J.; Tan, D.X.; Korkmaz, A.; Rosales-Corral, S.A. Melatonin and stable circadian rhythms optimize maternal, placental and fetal physiology. Hum. Reprod. Update 2014, 20, 293-307. [CrossRef] [PubMed]

31. Chuffa, L.G.A.; Lupi, L.A.; Cucielo, M.S.; Silveira, H.S.; Reiter, R.J.; Seiva, F.R.F. Melatonin Promotes Uterine and Placental Health: Potential Molecular Mechanisms. Int. J. Mol. Sci. 2020, 21, 300. [CrossRef] [PubMed]

32. Marseglia, L.; D'Angelo, G.; Manti, S.; Reiter, R.J.; Gitto, E. Potential Utility of Melatonin in Preeclampsia, Intrauterine Fetal Growth Retardation, and Perinatal Asphyxia. Reprod. Sci. 2016, 23, 970-977. [CrossRef] [PubMed]

33. Brown, M.A.; Magee, L.A.; Kenny, L.C.; Karumanchi, S.A.; McCarthy, F.P.; Saito, S.; Hall, D.R.; Warren, C.E.; Adoyi, G.; Ishaku, S. The hypertensive disorders of pregnancy: ISSHP classification, diagnosis \& management recommendations for international practice. Pregnancy Hypertens. 2018, 13, 291-310. [PubMed]

34. Abumaree, M.; Stone, P.; Chamley, L. An in vitro model of human placental trophoblast deportation/shedding. Mol. Hum. Reprod. 2006, 12, 687-692. [CrossRef] [PubMed] 
35. Tong, M.; Kleffmann, T.; Pradhan, S.; Johansson, C.L.; DeSousa, J.; Stone, P.R.; James, J.L.; Chen, Q.; Chamley, L.W. Proteomic characterization of macro-, micro- and nano-extracellular vesicles derived from the same first trimester placenta: Relevance for feto-maternal communication. Hum. Reprod. 2016, 31, 687-699. [CrossRef]

36. Zhao, M.; Li, Y.; Xu, L.; Hickey, A.; Groom, K.; Stone, P.R.; Chamley, L.W.; Chen, Q. Melatonin prevents preeclamptic sera and antiphospholipid antibodies inducing the production of reactive nitrogen species and extrusion of toxic trophoblastic debris from first trimester placentae. Placenta 2017, 58, 17-24. [CrossRef] [PubMed]

37. Beriault, D.R.; Werstuck, G.H. Detection and quantification of endoplasmic reticulum stress in living cells using the fluorescent compound, Thioflavin T. Biochim. Biophys. Acta 2013, 1833, 2293-2301. [CrossRef]

38. Tang, Y.; Chen, Y.; Nursalim, Y.; Groom, K.; Hickey, A.; Chamley, L.; Chen, Q. Endoplasmic reticulum stress occurs in association with the extrusion of toxic extracellular vesicles from human placentae treated with antiphospholipid antibodies. Clin. Sci. 2020, 134, 459-472. [CrossRef] [PubMed]

39. Eggert, N.; Lund, J. The trapezoidal rule for analytic functions of rapid decrease. J. Comput. Appl. Math. 1989, 27, 389-406. [CrossRef]

40. Tong, M.; Chen, Q.; James, J.L.; Stone, P.R.; Chamley, L.W. Micro- and Nano-vesicles from First Trimester Human Placentae Carry Flt-1 and Levels Are Increased in Severe Preeclampsia. Front. Endocrinol. 2017, 8, 174. [CrossRef]

41. Shen, F.; Wei, J.; Snowise, S.; DeSousa, J.; Stone, P.; Viall, C.; Chen, Q.; Chamley, L. Trophoblast debris extruded from preeclamptic placentae activates endothelial cells: A mechanism by which the placenta communicates with the maternal endothelium. Placenta 2014, 35, 839-847. [CrossRef] [PubMed]

42. Colombo, M.; Raposo, G.; Thery, C. Biogenesis, secretion, and intercellular interactions of exosomes and other extracellular vesicles. Annu. Rev. Cell Dev. Biol. 2014, 30, 255-289. [CrossRef]

43. Sadovsky, Y.; Ouyang, Y.; Powell, J.S.; Li, H.; Mouillet, J.F.; Morelli, A.E.; Sorkin, A.; Margolis, L. Placental small extracellular vesicles: Current questions and investigative opportunities. Placenta 2020, 102, 34-38. [CrossRef]

44. Espinosa-Diez, C.; Miguel, V.; Mennerich, D.; Kietzmann, T.; Sanchez-Perez, P.; Cadenas, S.; Lamas, S. Antioxidant responses and cellular adjustments to oxidative stress. Redox Biol. 2015, 6, 183-197. [CrossRef]

45. Goulopoulou, S.; Davidge, S.T. Molecular mechanisms of maternal vascular dysfunction in preeclampsia. Trends Mol. Med. 2015, 21, 88-97. [CrossRef] [PubMed]

46. Socaciu, A.I.; Ionut, R.; Socaciu, M.A.; Ungur, A.P.; Barsan, M.; Chiorean, A.; Socaciu, C.; Rajnoveanu, A.G. Melatonin, an ubiquitous metabolic regulator: Functions, mechanisms and effects on circadian disruption and degenerative diseases. Rev. Endocr. Metab. Disord. 2020, 21, 465-478. [CrossRef] [PubMed]

47. Nakazawa, K.; Kanakura, Y.; Kometani, K.; Iwasaki, S.; Yosimura, Y. Study on melatonin in human and rat placental tissue. Placenta 1999, 20 (Suppl. S1), 467-474. [CrossRef]

48. Valenzuela, F.J.; Vera, J.; Venegas, C.; Pino, F.; Lagunas, C. Circadian System and Melatonin Hormone: Risk Factors for Complications during Pregnancy. Obstet. Gynecol. Int. 2015, 2015, 825802. [CrossRef]

49. Hobson, S.R.; Wallace, E.M.; Kingdom, J.C.; Hodges, R.J. A Randomized Double-Blinded Placebo-Controlled Intervention Trial of Melatonin for the Prevention of Preeclampsia in Moderate- and High-Risk Women: The MELPOP Trial. Methods Mol. Biol. 2018, 1710, 347-352. [PubMed]

50. Duckitt, K.; Harrington, D. Risk factors for pre-eclampsia at antenatal booking: Systematic review of controlled studies. BMJ 2005, 330, 565. [CrossRef] [PubMed]

51. Hannan, N.J.; Binder, N.K.; Beard, S.; Nguyen, T.-V.; Kaitu'u-Lino, T.J.; Tong, S. Melatonin enhances antioxidant molecules in the placenta, reduces secretion of soluble fms-like tyrosine kinase 1 (sFLT) from primary trophoblast but does not rescue endothelial dysfunction: An evaluation of its potential to treat preeclampsia. PLoS ONE 2018, 13, e0187082. [CrossRef]

52. Lau, S.Y.; Guild, S.J.; Barrett, C.J.; Chen, Q.; McCowan, L.; Jordan, V.; Chamley, L.W. Tumor Necrosis Factor-Alpha, Interleukin-6, and Interleukin-10 Levels are Altered in Preeclampsia: A Systematic Review and Meta-Analysis. Am. J. Reprod. Immunol. 2013, 70, 412-427. [CrossRef]

53. Chen, L.; Liu, B.; Zhao, H.; Stone, P.; Chen, Q.; Chamley, L. IL-6, TNF [alpha] and TGF [beta] Promote Nonapoptotic Trophoblast Deportation and Subsequently Causes Endothelial Cell Activation. Placenta 2010, 31, 75-80. [CrossRef] [PubMed]

54. Chen, Q.; Viall, C.; Kang, Y.; Liu, B.; Stone, P.; Chamley, L. Anti-phospholipid antibodies increase non-apoptotic trophoblast shedding: A contribution to the pathogenesis of pre-eclampsia in affected women? Placenta 2009, 30, 767-773. [CrossRef] [PubMed]

55. Tong, M.; Tsai, B.W.; Chamley, L.W. Antiphospholipid antibodies and extracellular vesicles in pregnancy. Am. J. Reprod. Immunol. 2021, 85, e13312. [CrossRef]

56. Viall, C.A.; Chen, Q.; Liu, B.; Hickey, A.; Snowise, S.; Salmon, J.E.; Stone, P.R.; Chamley, L.W. Antiphospholipid antibodies internalised by human syncytiotrophoblast cause aberrant cell death and the release of necrotic trophoblast debris. J. Autoimmun. 2013, 47, 45-57. [CrossRef] [PubMed]

57. Gerasimova, E.M.; Fedotov, S.A.; Kachkin, D.V.; Vashukova, E.S.; Glotov, A.S.; Chernoff, Y.O.; Rubel, A.A. Protein Misfolding during Pregnancy: New Approaches to Preeclampsia Diagnostics. Int. J. Mol. Sci. 2019, 20, 6183. [CrossRef] [PubMed]

58. Hobson, S.R.; Gurusinghe, S.; Lim, R.; Alers, N.O.; Miller, S.L.; Kingdom, J.C.; Wallace, E.M. Melatonin improves endothelial function in vitro and prolongs pregnancy in women with early-onset preeclampsia. J. Pineal Res. 2018, 65, e12508. [CrossRef] 